\title{
Effect of Following Guidelines on Pharmacological Managements in Adult Patients with Type 2 Diabetes on Glycemic Outcomes
}

\author{
Hamed Abdelaziz Deraz ${ }^{1}$, Nagwa Mohamed Shawky ${ }^{1}$, Ahmed Salah Al Allam ${ }^{1}$, and Reem Saad Abujnah ${ }^{* 2}$ \\ ${ }^{1}$ Department of Internal Medicine, Faculty of Medicine, Zagazig University, Egypt. \\ ${ }^{2}$ Department of Internal Medicine, Faculty of Medicine, El Mergeb University, Libya. \\ *Corresponding Author: Reem Saad Abujnah, Mobil: +218 91-4948816, E-mail: reem18634@gmail.com
}

\begin{abstract}
Background: The prevalence of diabetes among hospitalized patients is high. One out of 4 hospitalized patients has diabetes; thus, treating hyper- or hypoglycemia represents an everyday challenge in hospitals worldwide.

Objective: This study aimed to assess the level of adherence to current American practice guidelines for inpatient pharmacologic management of type 2 diabetes and its effect on glycemic outcomes.

Patients and Methods: A prospective study was conducted in Internal Medicine Department, Faculty of Medicine, Zagazig University in the period from April 2020 to April 2021. It included 50 patients with type 2 diabetes who were treated with insulin and/or other antihyperglycemic drugs. They were followed up during their hospital stay for hyperglycemic and hypoglycemic episodes. Results: Mean capillary blood glucose measurement (CBGM) throughout three days were higher among Guideline adherence group than Guideline non-adherence group (12.6 \pm 1.04 vs. 5.2 \pm 1.3$)$ with statistically significant difference $\mathrm{p}<0.0001$. In addition, $88.0 \%$ of Guideline adherence group CBGM was measured four times or more per day. The incidence of hyperglycemic reading $(12.0 \%$ in Guideline adherence group and $36.0 \%$ in Guideline non- adherence group) showed statistically significant difference $p=0.047$. Conclusions: There is a good level of adherence to the current American guidelines for inpatient management of type 2 diabetes. The level of adherence is greater with more training and clinical seniority.
\end{abstract}

Key words: Diabetes mellitus, Glycemic, Guidelines, Type 2 Diabetes.

\section{INTRODUCTION}

Diabetes mellitus (DM) is a complex chronic illness associated with a state of high blood glucose level, or hyperglycemia, occurring from deficiencies in insulin secretion, action, or both. The chronic metabolic imbalance associated with this disease puts patients at high risk for long-term macro- and microvascular complications, which if not provided with high quality care, lead to frequent hospitalization and complications $^{(\mathbf{1})}$. The clinical diagnosis of diabetes is reliant on either one of the four plasma glucose (PG) criteria: elevated (i) fasting plasma glucose (FPG) $(>126$ $\mathrm{mg} / \mathrm{dL}$ ), (ii) $2 \mathrm{~h} \mathrm{PG}$ during a 75 -g oral glucose tolerance test (OGTT) (>200 mg/dL), (iii) random PG (>200 $\mathrm{mg} / \mathrm{dL}$ ) with classic signs and symptoms of hyperglycemia, or (iv) hemoglobin A1C level $>6.5 \%$. Recent American Diabetes Association (ADA) guidelines have advocated that no one test may be preferred over another for diagnosis. The recommendation is to test all adults beginning at age 45 years, regardless of body weight, and to test asymptomatic adults of any age who are overweight or obese, present with a diagnostic symptom, and have at least an additional risk factor for development of diabetes $^{(2)}$.

T2DM is a leading cause of morbidity and mortality and is a significant factor in increasing healthcare costs due to its extensive complications. The American Diabetes Association estimates the annual costs associated with T2DM to be over \$300 billion in 2017 . In January 2017, the American Diabetes Association and American Academy of Family Physicians labeled T2DM as a chronic progressive disease. However, both clinical experience and scientific studies have shown that bringing progression to a standstill and even reversing the clinical manifestations of T2DM should be considered an achievable clinical outcome ${ }^{(3)}$.

The prevalence of hyperglycemia in noncritically ill patients with diabetes is estimated to be about $25 \%$. One out of 4 hospitalized patients has diabetes; reasons for this high rate, in addition to the physiologic state, are related primarily to inadequate prescribing, monitoring and communication practices; thus, treating hyper- or hypoglycemia represents an everyday challenge in hospitals worldwide ${ }^{(4,5)}$. Hyperglycemia during admission is associated with increased rate of complications and longer hospitals stays; hence, the inpatient care of diabetes patients accounts for a substantial proportion of total health costs ${ }^{(6,7)}$.

The role of glucose control during hospitalization has been a subject of debate recently, as has the choice of insulin regimens. The first landmark trials on glycemic targets were performed in intensive care units. van den Berge et al. ${ }^{(8)}$ reported that intensive insulin treatment with a glycemic goal of $\leq 110 \mathrm{mg} / \mathrm{dl} \quad(6.2$ $\mathrm{mmol} / \mathrm{L}$ ) reduced in-hospital morbidity and mortality; however, subsequent trials failed to confirm this finding of reduced mortality with intensive glycemic control in critically ill patients ${ }^{(9)}$.

So we designed this study to assess the level of adherence to current American practice guidelines for inpatient pharmacologic management of type 2 diabetes and its effect on glycemic outcomes. 


\section{PATIENT AND METHODS}

This study was conducted on 50 patients with type 2 diabetes who were treated with insulin and/or other antihyperglycemic drugs (i.e. not diet controlled) in Internal Medicine Department, Faculty of Medicine, Zagazig University.

\section{Ethical consent:}

Written informed consent was obtained from all participants and the study was approved by the Research Ethics Committee of the Faculty of Medicine, University of Zagazig. Studies have been performed on research with human subjects in accordance with the Code of Ethics of the World Medical Association (Declaration of Helsinki).

All participants satisfied the following inclusion criteria; Patients with type 2 diabetes who are treated with insulin and/or other antihyperglycemic drugs (i.e. not diet controlled). Patients not on nil per os (NPO) according to their initial admission orders.

\section{Exclusion criteria:}

1. Patients with type of diabetes other than type 2 .

2. Patients on non-pharmacological treatment of diabetes

3. Patients on NPO according to their initial admission orders.

4. Patients who had admission diagnoses of hypoglycemia.

5. Patients who had admission diagnosis hyperglycemic hyperosmolar state or diabetic ketoacidosis.

6. Patients who were discharged from the hospital in less than 24 hours.

Studied patients were divided into two groups: Group I (Guideline adherent group): Twenty five diabetic patients were adherent if they continued on prehospitalization medications (oral antihyperglycemic, insulin or both) or if they received, at minimum, basal intermediate long-acting insulin.

Group II (Guideline non-adherent group): Twenty five diabetic patients managed by withholding home antihyperglycemic therapy, and whose glycemic control managed exclusively by using a reactive sliding scale alone, or no action was taken.

All participants were subjected to:

1. Full history taking including personal data: name, age and gender.

2. Full clinical examination: with special attention to body mass index (BMI). Admission diagnoses were categorized in a system-based pattern, and the severity of comorbidities was calculated using the Charlson morbidity index.

3. Prehospitalization diabetes medications taken at home were categorized into oral hypoglycemics, insulin or a combination of both. The seniority of the person writing the initial admission orders was documented.

\section{Laboratory investigations included:}

- Complete blood count (by automated blood counter).

- Glycosylated hemoglobin (by high performance liquid chromatography-ultraviolet detector).

- Capillary blood glucose measurement (CBGM) for the first 3 days of admission (before breakfast, before lunch, before dinner and before sleep).

- Kidney function tests including serum creatinine and blood urea by colorimetric method.

The patients were followed up during their hospital stay for hyperglycemic (fasting capillary blood glucose $>140 \mathrm{mg} / \mathrm{dL}$ or random blood glucose $>180$ $\mathrm{mg} / \mathrm{dL}$ ) or hypoglycemic episodes (capillary blood sugar $<70 \mathrm{mg} / \mathrm{dL}$ ).

\section{Measurement of HbA1c:}

A preparation of hemolyzed whole blood is mixed with a weakly binding cation-exchange resin. The non-glycosylated hemoglobin $\left(\mathrm{HbA}_{0}\right)$ binds to the resin, leaving $\left(\mathrm{HbA}_{1}\right)$ free to be removed by means of a resin separator in the supernate. The percent of $\mathrm{HbA}_{1}$ is determined by measuring the absorbance values at 415 $\mathrm{nm}$ of the $\mathrm{HbA}_{1}$ fraction and of the total $\mathrm{Hb}$ fraction, calculating the ratio of absorbance (R), and comparing this ratio to that of a glycohemoglobin standard carried through the same procedure. Results are expressed as $\mathrm{HbA}_{1}$ but can be converted or derived as $\mathrm{HbA}_{1} \mathrm{c}$ by using a conversion factor or when using an $\mathrm{HbA}_{1} \mathrm{c}$ value for the standard.

\section{Total hemoglobin assay:}

- Pipette $5 \mathrm{ml}$ deionized water into tubes labeled Standard (S), Unknown (U) and Control (C).

- Pipette $0.02 \mathrm{ml}(20 \mu \mathrm{l})$ of hemolysate into appropriately labeled tube. Mix well and transfer to cuvette for absorbance reading.

- Read absorbance $\left(\mathrm{A}_{\mathrm{tot}}\right)$ of standard, Unknown and control versus water at $415 \mathrm{~nm}$ within 60 minutes.

\section{Statistical Analysis:}

All data were collected, tabulated and statistically analyzed using SPSS 20.0 for windows (SPSS Inc., Chicago, IL, USA 2011). Quantitative data were expressed as the mean \pm SD and median (range), and qualitative data were expressed as absolute frequencies (number) and relative frequencies (percentage). Independent samples Student's t-test was used to compare between two groups normally distributed variables. While Mann Whitney U test was used for non-normally distributed variables. Percent of categorical variables were compared using Chi-square test or Fisher exact test when appropriate. All tests were two sided. P-value $<0.05$ was considered statistically significant $(\mathrm{S})$.

\section{RESULTS}

Table 1 reveals that there was no statistical significant difference between both groups regarding sociodemographic characteristics. 
Table (1): Comparison of sociodemographic characteristics among both groups

\begin{tabular}{|c|c|c|c|c|c|c|}
\hline & \multicolumn{4}{|c|}{ Studied groups } & \multirow[b]{2}{*}{$\chi^{2}$} & \multirow[b]{2}{*}{ p-value } \\
\hline & \multicolumn{2}{|c|}{$\begin{array}{l}\text { Guideline adherence } \\
\text { Group (N. 25) }\end{array}$} & \multicolumn{2}{|c|}{\begin{tabular}{|c|}
$\begin{array}{c}\text { Guideline non- adherence } \\
\text { group (N. 25) }\end{array}$ \\
\end{tabular}} & & \\
\hline $\begin{array}{l}\text { Age per years } \\
\text { Mean } \pm \text { SD } \\
\text { Median (range) }\end{array}$ & \multicolumn{2}{|c|}{$\begin{array}{l}57.64 \pm 7.8 \\
57(43-74)\end{array}$} & \multicolumn{2}{|c|}{$\begin{array}{c}58.4 \pm 8.8 \\
58(43-76)\end{array}$} & $\mathrm{t}=0.32$ & 0.75 \\
\hline Gender & N. & $\%$ & N. & $\%$ & & \\
\hline $\begin{array}{l}\text { Females } \\
\text { Males }\end{array}$ & $\begin{array}{l}13 \\
12\end{array}$ & $\begin{array}{l}52.0 \\
48.0\end{array}$ & $\begin{array}{l}12 \\
13\end{array}$ & $\begin{array}{l}48.0 \\
52.0\end{array}$ & 0.08 & 0.78 \\
\hline $\begin{array}{l}\text { BMI } \\
\text { Normal } \\
\text { Overweight } \\
\text { Obese }\end{array}$ & $\begin{array}{c}7 \\
8 \\
10\end{array}$ & $\begin{array}{l}28.0 \\
32.0 \\
40.0\end{array}$ & $\begin{array}{c}10 \\
8 \\
7\end{array}$ & $\begin{array}{l}40.0 \\
32.0 \\
28.0\end{array}$ & 1.05 & 0.59 \\
\hline $\begin{array}{l}\text { Mean } \pm \text { SD } \\
\text { Median }\end{array}$ & \multicolumn{2}{|c|}{$\begin{array}{l}28.6 \pm 5.1 \\
28.2\end{array}$} & \multicolumn{2}{|c|}{$\begin{array}{l}27.9 \pm 5.1 \\
27.8\end{array}$} & $? ?$ & $? ?$ \\
\hline
\end{tabular}

$\chi^{2}$ Chi square test, $\mathrm{t}=\mathrm{t}$ test.

Table 2 demonstrates that there was statistically significant difference between both groups regarding intake of oral hypoglycemic, insulin injection, and insulin initiation.

Table (2): Comparison of treatment regimen among both groups

\begin{tabular}{|c|c|c|c|c|c|c|}
\hline & \multicolumn{4}{|c|}{ Studied groups } & \multirow{3}{*}{$\chi^{2}$} & \multirow{3}{*}{ p-value } \\
\hline & \multicolumn{2}{|c|}{\begin{tabular}{|c|}
$\begin{array}{c}\text { Guideline adherence } \\
\text { group (N. 25) }\end{array}$ \\
\end{tabular}} & \multicolumn{2}{|c|}{$\begin{array}{c}\text { Guideline non- } \\
\text { adherence group (N. 25) }\end{array}$} & & \\
\hline & N. & $\%$ & N. & $\%$ & & \\
\hline $\begin{array}{l}\text { Oral hypoglycemic } \\
\text { No } \\
\text { Yes }\end{array}$ & $\begin{array}{c}9 \\
16\end{array}$ & $\begin{array}{l}36.0 \\
64.0\end{array}$ & $\begin{array}{c}18 \\
7\end{array}$ & $\begin{array}{l}72.0 \\
28.0\end{array}$ & 6.5 & 0.01 \\
\hline $\begin{array}{c}\text { Insulin } \\
\text { No } \\
\text { Yes }\end{array}$ & $\begin{array}{c}21 \\
4\end{array}$ & $\begin{array}{l}84.0 \\
16.0\end{array}$ & $\begin{array}{l}12 \\
13\end{array}$ & $\begin{array}{l}48.0 \\
52.0\end{array}$ & 7.2 & 0.007 \\
\hline $\begin{array}{c}\text { Combined } \\
\text { No } \\
\text { Yes } \\
\end{array}$ & $\begin{array}{c}20 \\
5 \\
\end{array}$ & $\begin{array}{l}80.0 \\
20.0\end{array}$ & $\begin{array}{c}20 \\
5\end{array}$ & $\begin{array}{l}80.0 \\
20.0\end{array}$ & 0 & 1 \\
\hline $\begin{array}{c}\text { Insulin initiation } \\
\text { BBI } \\
\text { SSI } \\
\text { No }\end{array}$ & $\begin{array}{c}18 \\
0 \\
7\end{array}$ & $\begin{array}{c}72.0 \\
.0 \\
28.0\end{array}$ & $\begin{array}{c}0 \\
14 \\
11\end{array}$ & $\begin{array}{c}0.0 \\
56.0 \\
44.0\end{array}$ & 32.8 & $<0.0001$ \\
\hline
\end{tabular}

$\chi^{2}$ Chi square test, BBI: basal-bolus insulin, SSI: sliding scale insulin.

Concerning mean CBGM throughout three days, it was significantly higher among Guideline adherence group than Guideline non-adherence group. In addition, $88.0 \%$ of Guideline adherence group used to measure CBGM four times or more per day (Table 3).

Table (3): Comparison of CBGM among both groups

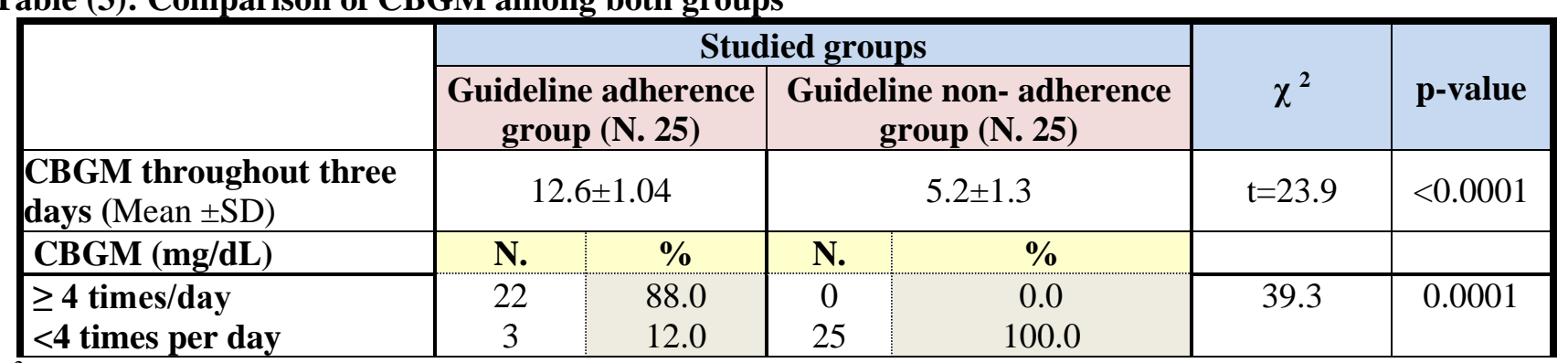

$\chi^{2}$ Chi square test $\mathrm{t}=\mathrm{t}$ test of significant

Table 4 demonstrates that incidence of hyperglycemic reading. The difference was statistically significant between the two groups. Relative risk of hyperglycemia was three times more among Guideline non-adherence group compared to Guideline adherence group. On other hand, there was statistically non-significant difference for occurrence of hypoglycemic reading among both group. Relative risk of blood glucose uncontrolled was 3.2 times more among Guideline non-adherence group compared to Guideline adherence group. 
Table (4): Comparison of hyperglycemic and hypoglycemic reading among both groups

\begin{tabular}{|c|c|c|c|c|c|c|c|}
\hline & & Studi & gro & & & & \\
\hline & Guide & $\begin{array}{l}\text { dherence } \\
\text { p } \\
5\end{array}$ & & $\begin{array}{l}\text { e non- } \\
\text { group } \\
5\end{array}$ & RR & $\chi^{2}$ & p-value \\
\hline No & 22 & 88.0 & 16 & 64.0 & 3 & 3.7 & 0.047 \\
\hline Yes & 3 & 12.0 & 9 & 36.0 & & & \\
\hline $\begin{array}{c}\text { Hypoglycemic Reading } \\
\text { No } \\
\text { Yes }\end{array}$ & $\begin{array}{c}23 \\
2\end{array}$ & $\begin{array}{c}92.0 \\
8.0\end{array}$ & $\begin{array}{c}18 \\
7\end{array}$ & $\begin{array}{l}72.0 \\
28.0\end{array}$ & 3.5 & $\mathrm{f}$ & 0.14 \\
\hline $\begin{array}{l}\text { Blood glucose } \\
\text { Controlled } \\
\text { Uncontrolled }\end{array}$ & $\begin{array}{c}20 \\
5\end{array}$ & $\begin{array}{l}80.0 \\
20.0\end{array}$ & $\begin{array}{c}9 \\
16\end{array}$ & $\begin{array}{l}36.0 \\
64.0\end{array}$ & 3.2 & 9.9 & 0.002 \\
\hline
\end{tabular}

$\mathrm{RR}=$ Relative risk $\chi^{2}$ Chi square test $\mathrm{f}=$ Fisher Exact test

Table 5 demonstrates that length of hospital stay in days was reduced by $32 \%$ for Guideline adherence group.

Table (5): Comparison of length hospital stay in days among both groups

\begin{tabular}{|c|c|c|c|c|c|}
\hline & \multicolumn{2}{|c|}{ Studied groups } & \multirow[b]{2}{*}{$\begin{array}{l}\text { Effect of } \\
\text { Guideline } \\
\text { adherence }\end{array}$} & \multirow[b]{2}{*}{$\chi^{2}$} & \multirow[b]{2}{*}{ p-value } \\
\hline & $\begin{array}{c}\text { Guideline } \\
\text { adherence } \\
\text { group } \\
\text { N. } 25\end{array}$ & $\begin{array}{c}\text { Guideline } \\
\text { non- adherence } \\
\text { group } \\
\text { N. } 25\end{array}$ & & & \\
\hline $\begin{array}{l}\text { Length hospital stay/ day } \\
\text { Mean } \pm \text { SD }\end{array}$ & $4.7 \pm 1.8$ & $6.5 \pm 2.2$ & $\begin{array}{c}\% \text { of reduction of } \\
\text { hospital stay per } \\
\text { day }=32 \%\end{array}$ & $\mathrm{t}=2.9$ & 0.004 \\
\hline
\end{tabular}

$\chi^{2}$ Chi square test $\mathrm{t}=\mathrm{t}$ test of significant

\section{DISCUSSION}

In the present study, there was no statistical significant difference between both groups regarding sociodemographic characteristics. This came in agreement with Alkhiari et al. ${ }^{(5)}$ who found that baseline characteristics, including age and gender were not significant predictors of guideline-based care.

In the present study, there was statistical insignificant difference between both groups regarding admission time, the admitting physician's seniority. Whereas there was statistical significant difference between both groups regarding consulting specialized team. It appears that majority $(80.0 \%)$ of guideline adherence group; were consulting specialized team. In agreement with our study, Alkhiari et al. ${ }^{(5)}$ found that there was no significant difference between the studied groups regarding admission time while the admitting physician's seniority significantly predicted guideline-adherent care and this was in disagreement with our study. The percentage of admitting health-care providers who were following guideline-adherent care during the admission was $76 \%$ in the combined cohort of junior residents/medical students, whereas it was $96 \%$ and $92 \%$ for senior residents and attending physicians, respectively $(\mathrm{p}=0.05)$.
Insulin is the preferred treatment of hospitalized patients with sustained hyperglycemia, and several different insulin regimens are used worldwide. An insulin regimen with basal insulin 1 to 2 times daily and bolus insulin at the main meals are recommended by American Diabetes Association for the inpatient management of diabetes ${ }^{(9)}$, and the sole use of sliding scale insulin (SSI), i.e., fast-acting insulin as correction insulin when blood glucose is above target, is strongly discouraged. However, SSI is still used in many countries. The reason for the persistent use of SSI regimens is unclear and may simply be due to clinical inertia.

In the current study, regarding mean CBGM throughout three days, it was higher among Guideline adherence group than Guideline non-adherence group with statistically significant difference. In addition, $88.0 \%$ of Guideline adherence group used to measure CBGM four times or more per day while in nonadherent group $100 \%$ of CBGM was measured less than 4 times per day. This came in agreement with Alkhiari et al. ${ }^{(5)}$ who found that the mean number of CBGMs in the first 3 days of admission was 9.8 $(\mathrm{SD}=3.6)$ in the adherent group versus $8.0(\mathrm{SD}=3.6)$ in the non-adherent group with statistically significant difference $(\mathrm{p}=0.05)$. also, CBGMs were ordered 4 times a day in $90 \%$ of the patients in the adherent 
group as compared to nearly $70 \%$ of those in the nonadherent group $(\mathrm{p}=0.02)$.

In the present study regarding incidence of hyperglycemic reading $(12.0 \%$ in Guideline adherence group and $36.0 \%$ in Guideline nonadherence group), the difference was statistically significant. Relative risk of hyperglycemia was three times more among Guideline non-adherence group compared to Guideline adherence group. On other hand, there was statistically non-significant difference for occurrence of hypoglycemic reading among both group. Relative risk of blood glucose uncontrolled was 3.2 times more among Guideline non-adherence group compared to Guideline adherence group. This came in agreement with Alkhiari et $\boldsymbol{a l}^{(5)}$ who found that hyperglycemia values composed $43 \%$ of CBGMs in the adherent group versus $64 \%$ of CBGMs in the nonadherent group $(\mathrm{p}=0.01)$. Hypoglycemic values composed $2 \%$ of CBGMs in the adherent group versus $1 \%$ of CBGMs in the non-adherent group. The mean proportion of hypoglycemia was small and without a significant difference between the groups $(\mathrm{p}=0.21)$. In the adherent group, only 54\% of CBGMs were found to be in target as compared to $35 \%$ in the non-adherent group $(\mathrm{p}=0.02)$.

In the present study, the length of hospital stay in days was reduced by $32 \%$ for Guideline adherence group. In agreement with our study, Martin et al. ${ }^{(10)}$ found that hyperglycemia due to non-adherent guideline during hospitalization is associated with increased length of hospital stay. Increased glycemic variability has also been associated with increased length of stay in patients with type 2 diabetes. In disagreement with our study, Christensen et al. (7) found no consistent association between insulin regimen and length of stay. However they found sliding scale insulin treatment might result in greater glycemic variability than BBI treatment.

\section{CONCLUSIONS}

There is a good level of adherence to the current American guidelines for inpatient management of type 2 diabetes. The level of adherence is greater with more training and clinical seniority. Junior residents are likely to need more extensive education concerning the American guidelines. Hyperglycemic episodes were found more commonly in patients who did not receive guidelinebased care. Hypoglycemia was uncommon, and though the numbers were small, it did not appear to be more common in the guideline-adherent group, which may alleviate physicians' fears that providing adequate insulin to hospitalized patients will cause hypoglycemia.

\section{REFERENCES}

1. Chaudhury A, Duvoor C, Dendi $R$ et al. (2017): Clinical review of antidiabetic drugs: implications for type 2 diabetes mellitus management. Frontiers in Endocrinology, 8: 6-9.

2. American Diabetes Association (2019): 2. Classification and diagnosis of diabetes: standards of medical care in diabetes-2019. Diabetes Care, 42(1): 13-28.

3. American Diabetes Association (2018): Economic costs of diabetes in the US in 2017. Diabetes Care, 41(5): 917-928.

4. Bach L, Ekinci E, Engler D et al. (2014): The high burden of inpatient diabetes mellitus: the Melbourne Public Hospitals Diabetes Inpatient Audit. Medical Journal of Australia, 201(6): 334-338.

5. Alkhiari R, Alzayer H, Aljazeeri J et al. (2018): Adherence to guidelines for inpatient pharmacologic management of type 2 diabetes in adults and glycemic outcomes. Canadian Journal of Diabetes, 42(2): 158162.

6. Whitston M, Chung S, Henderson J et al. (2012): What can be learned about the impact of diabetes on hospital admissions from routinely recorded data?. Diabetic Medicine, 29(9): 1199-1205.

7. Christensen M, Gotfredsen A, Nørgaard K (2017): Efficacy of basal-bolus insulin regimens in the inpatient management of non-critically ill patients with type 2 diabetes: A systematic review and metaanalysis. https://pubmed.ncbi.nlm.nih.gov/28067472/

8. van den Berghe $G$, Wouters P, Weekers $F$ et al. (2001): Intensive insulin therapy in critically ill patients. N Engl J Med., 345:1359-1367.

9. Griesdale D, de Souza $R$, van Dam $R$ et al. (2009): Intensive insulin therapy and mortality among critically ill patients: a meta-analysis including NICESUGAR study data. CMAJ., 180:821-827.

10. American Diabetes Association (2016): Standards of medical care in diabetes. Diabetes Care, 39(1): 1-109.

11. Martin W, Galligan J, Simpson S et al. (2015): Admission blood glucose predicts mortality and length of stay in patients admitted through the emergency department. Intern Med J., 45: 916-924. 